\title{
TURN TAKING STRATEGIES AND ITS RELATIONS TO EFL LEARNERS' PERSONALITY AND POWER IN THE INTERACTION OF ENGLISH CONVERSATION CLASS
}

\author{
Rohmatul Fitriyah Dewi \\ Universitas Negeri Surabaya \\ rohmatulfitri25@gmail.com \\ Suharsono \\ Universitas Negeri Surabaya \\ suharsono@unesa.ac.id \\ Ahmad Munir \\ Universitas Negeri Surabaya \\ ahmadmunir@unesa.ac.id
}

\begin{abstract}
Conversation is a pivotal spoken discourse needs to be practiced by EFL learners in the classroom. The successful of conversation can be achieved through turn taking strategies as the important part of the conversation. In fact, the way of EFL learners' turn taking strategies is influenced by the social context where it is employed. This study is aimed at examining social contexts based on how EFL learners' social personality and power influence their turn taking strategies during the interaction in English conversation class. Since this study depicts naturally occurring interaction, a qualitative approach is applied. By conducting participant observation, the data is gained from EFL learners spoken interactions by using audiorecording. The findings reveal that turn taking strategy employed by the learners result their different personality. Besides, the role of power also reflects the participants' social roles. The higher the status of participants, the more influence the language is in faceto-face interaction. In conclusion, the intertwined of language and social context is beneficial for the learners to motivate them in functioning the language.
\end{abstract}

Keywords:turn taking strategies, social context, conversation, spoken discourse

\section{A. INTRODUCTION}

Conversation is the process of interchanging opinions or feelings. It might occur in the daily practices of human life in a particular social and cultural milieu, such as greetings, asking and answer question. The study of conversation is essentially to be investigated as being of basic competencies, thus covering up by the concept of conversation analysis. Conversation analysis is an approach aiming to explore the structural organization of conversation such as adjacency pairs, preference organization, turn taking, feedback repairs, Rymes (2009), as the elements of spoken discourse. Therefore, it is precisely clear that conversation analysis area attempts to look an ordinary conversation occur (Paltridge, 2012), specifically, examining how people take and manage turns.

The first remark goal on the fundamental of conversation is when people taking a turn. Turn taking deals with controlling and regulating the conversations, by means, the notion of 


\section{Rohmatul Fitriyah D, Turn taking strategies and its relations}

interruptions and overlaps are systematically occurred which can be understood by the speakers due to the familiarity within cultural context(Thornbury and Slade, 2006). The possibility which will be going on, hence, the participants in the classroom will remain silent if nobody takes the floor in the beginning of conversation which actually the individual has the same opportunity to speak. Gorjian and Habibi (2015) mention that social relationship is established and maintained by each individual with others, as a result, turn taking can be achieved as well. In this case, classroom is the place where the instructors and the learners exchange turn taking in communicative event. Therefore, the most elementary unit on conversation, the heart, is turn taking.

Recently, learning English has become a familiar language to be practiced by many people at institutional school or outside school. It is can't be denied that the presence of English is involved due to a rapidly need of society who have the more interest to learn English as their foreign language. In this context, the community named English conversation class is provided to full the society's need by offering them a valuable lesson for joining to this speech events. The community is free for everyone who wants to participate, not only young learners but also adult learners. Based on these, in fact, conversation considers as the practice of language used, in which, it leads the negotiation of opinions and feelings expressed by the learners by which facilitating by the language (Pridham, 2001), in which, turn taking is the mostly revealed.

Unfortunately, turn taking as interactional patterns of interactions might be influenced by the context where it is employed. One vital dimension is the speakers' social contexts, as stated by Rymes (2009) that interactional context features influence the process of interaction production. In United States, Rymes (2009) says that most people use a type of IRE (InitiationResponse-Evaluation) patterns in domains of school and home interactions. They are culturally socialized within its habitual interaction that is, not universally acknowledged by other people. In Asian context such as Indonesia, where English is still not commonly used in a daily interaction, its turn taking patterns will be different with Western context, because of English is not socialized as the mother language.

The influence of social context actually not only come from the factors outside community but also the participants itself, that is, social personality and power. Personality focuses more on the individuals' characteristics, behaviors, feelings and attitudes (Mc Leod and Lively, 2006; Lightbrown and Spada, 2001). Meanwhile, power in this case is dealt with language; how its power has been influenced more to human lives (Fairclough, 2001). These part of social context also influences the participants' interaction that could be related to the way they do the turn taking strategies. Therefore, this present study is essential to examine social contexts based on 
Volume 4, Number 2, December 2018

how EFL learners' social personality and power influence their turn taking strategies during the interaction in English conversation class.

\section{B. REVIEW OF LITERATURE}

\section{Turn taking Strategies}

The term of turn taking is widely introduced by some linguists, Harvey Sacks, Emanuel A. Schegloff and Gail Jefferson. They believe that turn taking activity is commonly used through various social contexts for discussing in classroom, having a daily conversation etc. In the collaboration of their research, Sacks, Schegloff and Jefferson (1974) briefly characterize two segments of the simplest concept of systematic form in the organization of turn taking. Their first sequence is turn-constructional component which let a speaker to construct a turn, by utilizing some forms exist in English encompassing sentential, clausal, phrasal and lexical construction and adding with a feature of projectability. By which, further, those forms are adopted by Wong and Waring (2010), refer to turn-constructional unit (TCU).

The second sequence is turn allocation component. When there is a transition among speakers during a turn, those are relevant. It is a transition-relevance place. Hence, Sacks et.al (1974) design the rules to conform these speakers' transition that the allocation of next turn will be undertaken by selecting a current of next speaker and by using self-selection. Speakers who hold a talk or conversation must do turning the role of other speakers. To do so, speakers have to know how the rule of turn allocation is regularly organized. Participants can be under immense pressure to have talked, if the current speaker selects the next speaker to say. In order to accomplish a successful current-selects-next series, Wong and Waring (2010) offer the techniques of addressing terms, initiating action with gaze, initiating action which limits an eligibilityof respondents' prospects as to be the basic of turn-taking practices in pedagogical purposes, more specifically, in language teaching.

\section{Types of Turn taking Strategies}

Turn taking strategies refer to the ways how participants change and manage their roles when they become listener and speaker. According to Strenstrom (1994), there are three types of turn taking strategies that examining in each detail below:

1. Taking the turn 
Taking the turn refers to how each participant or speaker has a chance and a turn to speak while doing conversation. According to Strenstrom (1994), "taking the turn can be tricky". There are three parts of taking the turn, they are:

\section{a. Starting Up}

Starting up is the use of improper planning done by speakers when they are taking the turn. There are two types of starting up: hesitant start and clean start.Some speakers can use it to take the advantages by using available stalling devices such as filled pauses and verbal $<$ fillers $>$. Filled pause occurs when speakers utter a syllable that consists of a centralized vowel as a nucleus and an optional nasal coda (ub/um, in English) (Rose, 2012). A clean start is chararterized by the utterances ofwell, I mean and You know. It is produced by the speakers when they take a turn, but in the unprepared condition.

b. Taking Over

After doing starting up strategy, another speaker gives the response directly by taking over the turn. The position of first speaker is replaced by the second speaker as the listener. Stenstrom (1994) confirms that taking over strategy is connected to an uptake or a link, such as yes, no, but, etc. There are the occurrences of receiving the responses and following up the moves that are influenced by an uptake.

c. Interrupting

Other speaker or listener may interrupt anybody else (speaker) in the beginning and midst of current talk. Stenstrom (1994) categorizes two types of interrupting are alerts and metacomments. Alert is kind of signal, produced by certain speaker indicating the use of a louder and a higher pitch of voices. It indicates that the listener tries to stop the speaker's talk because he/she intends to say or inform valuable information. While meta-commentis used based on the situation when the speakers demand to comment on his/her talk by using polite utterances

\section{Holding the turn}

Holding the turn carries out talking (Stenstrom. 1994). It is about how the speaker wants to hold a chance, but they have difficulty in controlling and planning what the things have to say. The speakers need some devices to help them in avoiding the breakdown and taking over the turn by using filled pause or verbal fillers, silent pause, lexical repetition and new starts. Filled pause occurs when speakers utter a syllable that consists of a centralized vowel as a nucleus and an optional nasal coda (uh/um, in English). Other device is silent pause or unfilled pause. It 
refers to the interval/duration of silence within speech. It is syntactically and semantically strategy used by the current speaker to wait other speakers stop talking (Stenstrom, 1994). Lexical repetition is a device that used the same lexical item several times produced by the current speaker. To ongoing the talk, the speaker repeats a single word at the time.Moreover, a new start is the repetition of a sequence of one or more words immediately. It aims to avoid in getting lost when conducting the conversation.

\section{Yielding the turns}

Yielding the turn is how each participant or speaker is given a chance by the previous speaker to have a turn to speak. It means that the speaker becomes the listener for hearing the responses (Strenstrom, 1994). Yielding the turn consists of three types:(a) prompting is the speaker acts to the other speakers promptly in order to give responses. Providing a prompt response will automatically yield the turn by 'greeting', 'asking questions', 'asking apologizing', 'inviting', etc.(b) appealing, is one of yielding the turn by signaling other participants or speakers to get the feedbacks. Some of signaling words include 'question tag', 'all right', 'you know', etc and (c) giving up, is the speakers do giving up strategies because nothing more to say or think at the moment when other speaker utters something. Utilizing 'giving up' can be identified through yielding the turn at completion point in which the speakers are being silent. Moreover, they are also taking a long pause by uttering I will - e:m'.

\section{Social Contexts}

Social context is defined as how people interlace the social relationships in the field of communication. Rymes (2009) defines that social context is about the outside of social factor that gives the influence toward language-in-use. Classroom, in this case, is also part of discourse in which language is used by the participants of class. The notion of context and discourse are mingled, as defined by Dijk (2008) that talk, as communicative event in classroom, actually, is also the representation of participants' actions. Interaction in the classroom may be strongly driven by social context how learners do the interaction with their peers. Establishing mutual understanding of interaction needs to deal with how the language of talk is organized as well as how the factor of social context is influenced. Dijk (2008) proposes the structures of social context. Social context refers to the settings and happenings around to the individuals including personality, power and activities. The model comprises of two major points that are:

\section{a. Settings}




\section{Rohmatul Fitriyah D, Turn taking strategies and its relations}

Based on people's experiences, they will adapt where they supposed to stay and when it occurs. They need specific information with conforming to the contextual properties in social settings that establish the contexts of events through time, location and circumstances. Time, for human beings, is beneficial for their activities by bringing senses and recording all transitions during undergoing a life.The representation of time is controlled by social actors who conduct some communicative events (Dijk, 2008). For location or place, is said as a particular area or position typically inhabited by someone.The setting of place, in this respect, it does not describe a place in detail, rather than it comprises the supported aspects beyond, as mentioned by Smith (2001), in Dijk (2008), that are participants, types of interactions, discourse, social meaning and identity. Meanwhile, circumstance is a set of condition, with accompanying and modifying the events through the sets of place, time, social agent and manner.In fact, circumstances are influenced by some environmental factors such as noise that is created by some participants.

\section{b. Happenings}

Happening refers to something that lives, exists, and involves in certain events.In such scopes, two notions of actors and activities are interrelated. Actors, in this sense, are the participants in conducting action that is suitable to its social situations and social orders occur in the society. According to Dijk (2008), the factor which are influenced to the social actors, that of personality, social organization and mental. The first factor is personality that refers to a private life of someone. That is, every person has their own ways in behaving, thinking and feeling with regarding how individual attempts to understand their personality in social circumstances and how the various people come to value them.

In relation with social structure, personality focuses more on the individuals' characteristics, behaviors, feelings and attitudes (Mc Leod and Lively, 2006; Lightbrown and Spada, 2001). The second factor is social that relates to social organization or society. The factors are proposed by Dijk (2008), that are social roles and social relations. Social role is social structures of responsibilities, the organization of roles and the relations of social practices. To know how social relation works, Dijk (2008) puts the integration between power and dissent. The combination of both comes to the inputs of macro-micro aspects as well its sociocognitive of participants. The last factor is mental. It refers to the background knowledge of people; specifically it refers to their personal representations of events, accompanied by their own interests, views and perspectives based on their unique experiences. In this sense, mental encompasses knowledge, rules, opinions, intentions and goals (Dijk, 2008). 
In term of activities, it provides the necessary information controlling over speaking or writing in the partial actions, such as utterances of words. Dijk (2008) declares that through social action, the activities share its beliefs, knowledge, attitudes, identities and norms that conducted by the society. Additionally, the action is expected to perform and combine individual's personal goals and opinions.

\section{METHOD}

The subject of this study were EFL learners in one of the communities in Surabaya, namely English Conversation Class. This community is chosen since the researcher is also one the members that join and involve in the community. Considered as the public community, the learners also come from different social background such as students, workers, and other adult learners. In every meeting conducted, the learners consist of 10-25 members and it is held on every Wednesday. The conversation activities have action sequences of events, which are introduction, discussion and closing.

The researcher conducted participant observation as the main data collection. This technique is used to gain data of EFL spoken statements to know how social contexts are influenced to the learners' turn taking strategies in conversation by using audio recording. All of the data is based on the participants' of this study, as stated by Mackey and Gass (2005) that the data of participants' action and behaviors can be obtained from the observation. To confirm this phenomenon, an emic perspective can be obtained from its social context, i.e. classroom (McKay, 2006), by interacting with other members through a casual conversation and other relevant activities. In analysing the data, the study uses a qualitatitve approach by Miles et.al. (2014) include data condesation, data display and drawing conclusion.

\section{FINDINGS AND DISCUSSION}

\section{Findings}

In this section, the discussion is specialized to analyze the relations between turn taking strategies and participants' personality and power in the classroom discourse. These aspects that embodied with participants are called social contexts, and then further they are examined and elaborated to fit the member of class. Taking the turn plays is as the foundation stage in order to have a communicative talk in turn taking system. EFL learners might apply three types of taking the turn; they are starting up, taking over and interrupting. Each of those has different distribution depending on how each participant or learner in the class use them based on a 
context occur. To begin with, talking about starting up is one of ways to start the talk by focusing on the use of a hesitant start and a clean start.

Hesitant start reflects a temporarily delayed of the individual's speech in which it can be identified through a commonly used of 'uhm' and 'uh'; while a clean start contains sequential marker of 'well'. Regarded to these discourse markers in a spoken language, the producing of those devices are acceptable by some people in their spontaneous interaction, even in formal one. However, it can be denied that beyond the words uttered, there will be the significant contribution from those different EFL learners. Participant's personality in using hesitant start is not the same from the one whom using a clean start. For instance, see the excerpt 1 above:

\section{Excerpt 1}

52 I-1 : Oh...you don't have car. So, neighbor? What about yourneighbors who have car? Where they or your neighbor have nocar?

$53 \mathrm{L1} \quad$ : = Just few people, in the outside. Ada yang gadimasukkan.

54 I-1 : Ok. Oh I see..very interesting your kampung ((Laughing)). Okthank you, Steven.

55 1-1 : Uhhm..any..any..ideas for (0.4). Ok. Everybody must have idea uhh.. any other? Ricky! You must have idea to think, to talk about tonight. So, you ((Pointing)). Oh..oh..already.

TS-1/01/SU/HS

Based on the interaction above, "Uhhm..any...any..ideas for (0.4). Ok. Everybody must have idea ubh..any other? Ricky!...”. These utterances are performed by the instructors that he thinks about a certain idea to be discussed. By using a hesitant start, it can be seen that actually the instructor is having lack of content, which means no idea, so then he asks other participants' opinion. His position as instructor in the class gives him a benefit to control the floor. After being hesitated, he points one of the participants, by mentioning his name in order to help him in thinking the idea. Moreover, it also tries to save the speaker's positive face. Another a hesitant start is used by the participant in the excerpt 2 as follows:

\section{Excerpt 2}

76 I-1 : Another, please? Fitri..Fitri come! Fitri, any ideas to talk about..?

77 L3 :Uhm..uhm... maybe about ... maybe I have what is the idea about how teenagers now. The behavior of teenager that uhh...they tend to be more, what is it, like (0.5) uhh.. what is it, like independent, dependently. As it is effected by social media like instagram, or facebook and others. So, when the what is it, like the teenagers gather in the one place. So, it is only they must talk each other, right? But, they tend to uhhhyeahh...they tend to pay attention to their gadgets or their laptops and others. 
"Uhm..ubm..maybeabout.maybe I have what is the idea about how teenager now...." . In this context, its turn length 'uhm...uhm' shows a deep in taught of the speaker.

In a clean start, a clear response is expressed by how the participant answers a previous talk in interaction. The person who responses 'well', it shows that he/she is being orient listeners by paying attention to other person's talk from the beginning up to the end. See the excerpt below.

\section{Excerpt 3}

3 I-1: Ok. Well? $\uparrow$ STEVEN! Tell me where do you live? About your house. Do you life with your parents?

4 L1: =Yeah!

5 I-1: Do you live with your parent, yes? Who else in the house?

6 L1: =Mother and my uncle

TS-1/01/SU/CS

\section{Excerpt 4}

185 L1 :Well.Actually, I don't have any idea about uhhm... ourculture what will we...

$186 \mathrm{~L} 2$ :

$187 \mathrm{L1}:=\mathrm{I}$ am student. Student

[You student or?]

188 L2 : So, I think it is important to have that (0.7) --- university?

TS-1/01/SU/CS

Based on the interactions, his/her personality indicates that he/she is a straight forward person who gives a direct response to others. As being learner, producing a filler word to start up or a clean start in a talk is allowed that every learner is freely to express what they want to share.

Participants also can take over the turn without starting up phase. They can choose whether he/she wants to take over by utilizing either uptakes or links device. Nevertheless, each of them reflects the different participants' personality. For uptakes, it provides the two types of agreeing and disagreeing response. The example is above.

\section{Excerpt 5}

262 L4 : I am still young

263 L1 :Stiill young?

264 L4 : =I am still don't understand all about culture.

265 L3 : Just tell the culture that you feel now

266 L4 : Culture right now?

267 L3 :=Yeah! Maybe oour our period...our generation is different, right?

$268 \mathrm{~L} 1:=$ Yeah! It is same with me. I don't know about many culture here is 
Both learners give the same direct response by using uptake 'yeah'. A symbol of ' $=$ ' also indicate that the interaction in continuous context. The individual who takes over the turn by agreeing a previous statement, his/her personality is going straight forward person, which is, to the point and direct response by finishing the statements that he/she utters.

Meanwhile, a form of linking words such as 'but' and 'because' is a result of direct responses performed by the participants. The difference can be seen from how those links devices are used by them, specifically, in the unfinished statements. Here are the examples of the excerpts.

\section{Excerpt 6}

307 I-1 : I can't understand. How can make it? How can make it? Withoutmobile phone. Without TV and without boys. How many times?

308 L17 : Three years

309 I-1 and I-2 : Three years? Wuhhh...

310 L17 : But I get uhh unpredictable experience

311I-1 and I-2: What is that?

312 L17 : When I join..apa.. enroll in the university, finally what is it, I have a test covered by Ministry of Religious Affair. So that fromIndonesia it only uhh...how many students for that..

TS-2/02/TO/LK

\section{Excerpt 7}

232 L8 : If I learn English it is important now because ....::

233 I-1 : : [The answer is he doesn't learn English from the game, so maybe it is exception]

234 L8 : Because it is important for job, English is number one

$235 \mathrm{I}-2 \quad$ :Ok.

TS-2/02/TO/LK

The context of the excerpt 6 (TS-2/02/TO/LK) and excerpt 7 (TS-2/02/TO/LK) is about the participants' confidence to show his/her feeling by connecting the contrast idea.

There is no a smooth way to conduct taking a turn strategy during interaction. A situation that might be faced by the participants is having interruption. This moment of being interrupted is such a common thing found in our conversation. The people may interrupt other by using alerts and meta-comments. In the previous discussion, there are two different alerts used by the instructors, presented in excerpt 8 (TS-1/01/IT/AL) and excerpt 9 (TS-3/03/IT/AL). 


\section{Excerpt 8}

35 I-1 : Ok..so, uhh...do you like your..your home?

$36 \mathrm{~L} 1 \mathrm{:}=$ Very like it because the centre of $(0.5)$ and so many events in:::

37 I-1 : : So many what?

38 L1 : So many events

$39 \mathrm{I}-1 \quad:=$ Friends?

40 L1 : Events...events ((Audience's voices))

41 I-1 : What do you mean by events?

$42 \mathrm{~L} 1 \quad:$ : =So many events here, kaya...uhhm...festival

43 I-1 : So many events because it is ini the cii::: --- in the center of the city? So you are care free day for the example, in JalanTunjungan. Oh ya, I think the center is located very expressive

44 I-2 : HEY, last Sunday..last Sunday, it was a culture in flower painting

$45 \mathrm{I}-1 \quad:=$ Ohh...culture in flower painting..heemm..

TS-1/01/IT/AL

\section{Excerpt 9}

51 I-1 : The question is uhm everyone, time is money, yeah? What does it mean? Explain! What is wasting time?

$52 \mathrm{~L}+\mathrm{L} \quad$ : Waste time

53 I-1 : Yang dianggapmembuang-buangwaktuituapa? What is waste of time?

$54 \mathrm{~L} 4 \quad:=$ Waiting

55 I-1 : Singing!

56 L5 : Traffic!

57 I-1 : Ok, LOOK at this! (to a white board). Why I talk about time? Because time is important. Andapernablibatsebuahpintucandiya? If you look at temple, you know Hindu temple?

$58 \mathrm{~L}+\mathrm{L} \quad:=$ Yes

59 I-1 : Normally, Hindu temple itusepertiini ((While drawing)) uuh..moreover like this, and this is uhh..like this. Gini ya?

$60 \mathrm{~L}+\mathrm{L} \quad$ : Ohhh... ((Laughing while looking at a white board))

61 I-1 : Kala means when or time. Ok. Kala is time

TS-3/03/IT/AL

Based on the contexts, the interactions show that the first and the second instructor, both of them use direct interruption, that is, 'hey' and 'look'. These word choices of alerts perform their personality of being making a point in the interaction. Related to social role of them, they have a certain position in the class. They, as organizers of the community, attempt to take a leading role. Even, the participants have the interaction with others, they success to take their attentions. In other cases, meta-comment is used by the learner in excerpt 10 (TS-1/01/IT/MC).

\section{Excerpt 10}


204 L2 : The first one is to identify culture in our country. Assessment.Penilaian. Evaluating. What the nilaiapakabbudayaitubagusatautidak. How is your opinion? Budayaitusebagaipondasikarena ----

$205 \mathrm{~L} 3 \quad:=$ Uhmmm..apaya?Uhm...may I give some explanations?

206 L1 : : [Hey, maybe next people... ((Pointing)) I want to ....yeah]

207 L2 : : =It's ok. Free

208 L3 : I think uhh..in this.. in this discussion, the culture is uuh.. doesn'tbelong to ::: what is it like the pigeon. What it is like the...like the instructor has been explained just now...

TS-1/01/IT/MC

The utterances "May I give some explanations? Excuse me, may I give some explanations? May I give some explaination?'This context is actually the alerts used to talk with an older person; the learner's personality is being calm. The learner uses a polite request in an attempt to share his/her opinion, rather than a direct interruption due to still there is a distance among other learners. Thus, alert aims to save his/her positive face. Interruption in face-to-face interaction is to control the learners' contribution as dealing with the relations of power and language.

Furthermore, other significant manifestation of turn taking strategies is holding the turn. To hold a turn, person can apply some linguistics devices. Let's take one example in excerpt 11 (TS-1/01/HT).

\section{Excerpt 11}

209 L3 : I think uhh..in this.. in this discussion, the culture is uuh..doesn'tbelong to :::what is it like the pigeon...what it is like the...likethe instructor has been explained just now.. tentangtadiloh, tentangmerpati. But, the culture in Indonesia maybe uhh..it is...our culture that influenced...influenced by the Western.Jadiyang --- it influences by the Western, so maybe we can::: what it is like... I will take one example of the culture.Uhhmm, in my..in my.. what is it. In my..childhoud childhood, uhmm..19-ninety'st - one hundred and -- seribusembilanratusanlabya.Uhm, we as a child what it is very-really enjoyour ourdaily with friends... : =So.. I think now the children uhh...doesn't --- hasn't a place.... 
The context depicts how the learner has a turn to deliver what she thinks about a particular topic discussed. At the beginning the learner gives the detailed explanation of a topic, it seems that he/she has some obstacles in saying it fluently, but the learner still wants to continue the talk. As a consequence, it appears the use of linguistics devices in spoken language, such a as filled pause, silent, lexical repetition and new start stated by the learner. Aiming to maintain a floor, the speaker is intended not being afraid to be silence. It shows how the learner's personality of being struggle in facing his/her problem in speaking. By inserting an empty pause with 'uh' and 'uhm' (filled pause), adding an extra silent time (silent pause), repeating a certain word (lexical repetition) and starting the new statements (new start) are to make the conversation still going on. The power of language is also reflected by the ways how the speaker combines the sentences to be more thoughtful. The learner also adds some information related to a topic as the general schemata.

Turning to final turn taking strategies is yielding the turn. Yielding means giving a chance to other learners for having his/her turn. There are three ways that can be conducted to yield the turn. It comprises prompting, appealing and giving up. To stimulate learner's response in the interaction, the other learner may apply prompting strategy. Let's see the excerpts below.

\section{Excerpt 12}

270 L1 : How to protect our culture?((Looking at other learners)).It is simple. The government should make a curriculum that to all students that support uhh..that support too.. melestarikanituapa?to preserve Indonesian culture.

This curriculum to be used.. diadakan from elementary until the university...

\begin{tabular}{|c|c|}
\hline $271 \mathrm{L3}$ & $\begin{array}{l}\text { So that is related to education? } \uparrow \text {, } \\
\text { according to me to protect the culture is for the } \\
\text { for the teenager..uhh..we should what is it..like } \\
\text { join to the certain club... }\end{array}$ \\
\hline $272 \mathrm{~L} 2$ & [Please Reni! Write it down] \\
\hline 273 L1 & $:=$ Yeah \\
\hline 274 L2 & : And Reni, I hope you present it what you have written \\
\hline 275 L1 & : Government should protect the curriculum \\
\hline $276 \mathrm{~L} 4$ & : So what the reason to protect? \\
\hline 277 L3 & $\begin{array}{l}:=\text { According to me, what should be protected is the teenager culture. The one } \\
\text { that is the most familiar, the teenager }\end{array}$ \\
\hline $278 \mathrm{~L} 4$ & : There is the reason, why? \\
\hline 279 L3 & $:=$ Because teenager is become the central of everything \\
\hline $280 \mathrm{~L} 1$ & : Just discuss, don't stop! \\
\hline $281 \mathrm{~L} 3$ & $:=$ Yeah. What do you think about that? ((Pointing)) \\
\hline $282 \mathrm{~L} 2$ & : Number one? Number two? \\
\hline 283 L1 & $\begin{array}{l}\text { : Number one, the government should make curriculum for the...tostudents } \\
\text { from elementary until maybe university }\end{array}$ \\
\hline
\end{tabular}


The context in the excerpt 12 (TS-1/01/YT/PR), i.e. "bow to protect our culture?", "so that is related to education", "so what the reason to protect", "what do you think about that", and "number one? Number one"are the examples of prompting strategies performed by different learner in one context of discussion section. Not all individuals are being confidence to do a prompt by asking some questions, but based on these contexts, the learner's personality is being active to ask what they want to ask without considering misspelling in grammar or a good pronunciation. As a means of power, learning and practicing the language can be achieved together by them as long they have the same status as the learners of class.

Moreover, the attention and feedback are also intended to be concerned by the participants. To obtain them, they signal other learners by using appealing strategy. The signaling words used are 'right', 'are you know' and 'yeah' in the excerpt13 and excerpt 14as below.

\section{Excerpt 13}

167 L3 : According to you ((Pointing first speaker)) culture is really cultures? Kaya misalnyakerapansapi, dances, language, tapiaccording to me, culture can be what is it..the habitual activity of someone of the community or of uhh..the groups. It can be like that.

$168 \mathrm{~L} 2$ : =It is culture, but uhh..we discuss familiar. We discuss something common. Something common. When I::: I tallk about this culture, everybody knows...everybody knows.

$169 \mathrm{L3}:=$ : =eah!

170 L2 : Not only just observe it. It can be ---

$171 \mathrm{L1}:=$ Uhmm..maybe here, we have two opinion, right?

173 L3 : =Yeah!

174 L1 : Culture..culture..about habitual culture and culture uhh...

$175 \mathrm{~L} 3$

[As the identity]

TS-1/01/YT/AP

\section{Excerpt 14}

227 L13 : May I know, how much you spend your money there becauseyour punishment one word one thousand?

228 I-2 : =Ohhyeahh..one word one thousand ((Laughing))

229 L13 : And the second is uhh as long as I know uhh the boy like a game and his uhh learning English from the game. Are you know my statement?

230 L11 : =Yeah, ok. Game for practice (.)

231 I-1 : Not only boys. Some English for game. There are many games or gaming. 
The utterances such as "=Uhm...maybe here, we have two opinion, right?"and "are you know my statement'The learners who utilize appealing, their personality is making a definite understanding or conclusion before determining the final output that occurred in the interaction. The strategy contains most of informal language that it can be implemented by all the participants or member in that casual environment.

The last but not the least, the moment of nothing words or sentences to say may be faced by the learners in their interaction. They tend to giving up instance of continuing their talk. Referring to a previous finding, giving up strategy is done by the learners, shown in excerpt 15 and exceprt 16.

\section{Excerpt 15}

227 L2 : In Japan, it is Sumo. It is culture. The characteristic of Japanesepeople... that's culture, so it should be kept.

228 L1 : =Different idea, yeah?

229 L3 : = Javanese::: Javanese language maybe

$230 \mathrm{~L} 2$ : Not the language

$231 \mathrm{~L} 1 \quad: \mathrm{SO} \uparrow \uparrow$

232 L3 : Yes...yes language. Language is part of culture

233 L4 : =Yeah, but....

$234 \mathrm{~L} 2 \quad: \quad$ [Language is different...]

235 L1 : [Maybe uhh..we have choose one opinion, right?

$236 \mathrm{~L} 3$ and L4 : =Yeah

237 L1 : Because if we different opinion ::: until untilthe last of the end - e:m

238 L4 : =Yeah ((Laughing))

TS-1/01/YT/GU

\section{Excerpt 16}

79 L2 : BujangGanome is uhhm... friend of KelonoSewandono

$80 \mathrm{I}-1$ and I-2 : =Ohh, friend of KelonoSewandono ((Nodding)). Yes, I see

$81 \mathrm{~L} 2 \quad:=$ With the big nose and with uhh..mask, the mask is not used like that

((Touching he face)) maybe, but digigit

82I-1 : : =By bitting, right? By bitting the mask

$83 \mathrm{~L} 2 \quad:=$ Yes. So, in the..inthe..what is it. I mean --- e:m

$84 \mathrm{I}-1 \quad:=$ : $\quad$ Yes, by bitting the mask. They are always bit the mask

$85 \mathrm{~L} 2 \quad$ : They have attraction include uhmm..Dadak, number four

$86 \mathrm{I}-1 \quad:=$ Dadak number four?

$87 \mathrm{~L} 2 \quad:=$ Yes, and the last is Warok. Warok..he in the KelonoSewandono side

TS-2/02/YT/GU

Based on the interactions above, the utterances "Because if we have different opinion::: until until the last of the end-e:m"(exceprt 15) and "=Yes, So, in the...in the..what is it. I mean --- e:m (excerpt 16) 


\section{Rohmatul Fitriyah D, Turn taking strategies and its relations}

are the strategies for giving up. The end of each sentence "---e:m", indicates that he/she gives up the talk. The person personality can be captured that he/she doesn't have the struggle to overcome the difficulty they face because it is showed by the way he/she directly ends up the conversation without finishing it. The equal power of the learners allow them to have the same act to give up at completion point rather than being a long silent by doing self-constraints of discourse.

\section{Discussion}

The findings reveal the essential actors are needed. The engagement of social actors is demanded to focus on its specific social properties, situational situation and contextual of the participants (Dijk, 2008). In the realm, the other important thing to be equipped is social's personality, language and power. The findings of this study show that turn taking strategy employed by the learners result their different personality. One example of social personalities gained from holding the turn strategy, by means, the people who are directly hold the floor without starting up the turn is indicated as going straight person. As supported by Lightbrown and Spada (2001), personality is the reflection of the individual characteristics.

However, the way of learners is being talkativeness and dominance, also influenced by power. The findings reveal that power in this communicative event is dealt with the participants' social roles. In one case, the instructors are allowed to make direct interruption for other participants due to their power as the one who lead the community. Meanwhile, among learners or participants, they use a polite request to make interruption for older learner due to their distance. The higher status of participants, the more influence the language is in face-to-face interaction. It is supported by Fairclough (2001), contents, relations and subjects are done by the powerful participants in controlling a certain speech event.

According to Dijk (2008), social roles and social relations are integrated that can be composed with social realms where the relations among other participants.Meanwhile, referring to the participation of language users of community, Dijk (2008) confirms that mental factor should be owned by each individual as the key to share socially beliefs and opinions based on their schemata. It helps them to share the ideas if they know what is supposed to say with other participants. It is in accordance with a study done by Handford (2016). The study results that the intertwined of language and social context is beneficial for the learners to motivate them in functioning the language in forms of interpersonal and ideational. 
Volume 4, Number 2, December 2018

\section{E. CONCLUSION}

The purpose of this research is to examine howsignificant factors of social context which influence the participants to classroom interactions. Turn taking is, looking at the shifting of speakers and listeners turn in talks. While its strategies see how those types of strategies are applied by the speakers to establish the interactive communication. Principally, the ideal turn taking requires two persons only who speak, however, it might suit for more than that. This means that a context touches the participants of its community. The influences of participants' personality and power is also influenced how the way turn taking strategies are utilized by the learners. That is, it comes from societal roles of those participants as the reflection of the dominance of language use in conversation turn, so that power is also much influenced in this classroom discourse.

In conclusion, this study has been revealed that most turn taking strategies is applied by EFL learners as it is dealt with its micro social context.Based on the discussion and data analysis presented previously, the findings of this study can be used as the consideration to both theoritical and practical contributrions. Theoritically, this study supports the theory on turn taking strategies and social contexts as what the strategies and aspects influence beyond the participants' interaction in the classroom. Practically, the instructors can give more chance for the learners by practicing their spoken English without any boundaries.

\section{REFERENCES}

Dijk, T. A. (2008). Society and Discourse. How Social Contexts Influence Text and Talk. Cambridge: Cambridge University Press.

Fairclough, N. (2001). Language and Power. Second Edition. London and New York: Routledge Taylor and Francis Group.

Gorjian, B. And Habibi, P. (2015). The Effect of Conversation Strategies on the Classroom Interaction: The Case of Turn Taking. Journal of Applied Linguistics and Language Learning 2015, 1(1) pp. 14-23.

Hanford, M. (2016). The Dynamic Interplay between Language and Social Context in the Language Classroom: Interpersonal Turn Taking for EFL Learners in King, J. (2016). The Dynamic Interplay between Context and the Language Learner. UK: Palgrave Macmillan.

Lightbrown, P. M. and Spada, N. (2001). Factors Affecting Second Language Learningin Candlin, C. N. and Mercer, N. (2001). English Language Teaching in its Social Context. A Reader. London and New York: Macquarie University and The Open University.

Mackey, A. and Gass, M. S. (2005). Second Language Research. Methodology and Design. New Jersey: Lawrence Erlbaum Associates. 
McKay, S. L. (2006). Researching Second Language Classroom.Marwah, New Jersey: Lawrence Erlbaum Associates.

Mc Leod, J. D. and Lively, K. J. (2006). Social Structure and Personality in DeLamater, J. (2006). Handbook of Social Psychology. Springer Science and Business Media.

Paltridge, B. (2012). Discourse Analysis. An Introduction: 2nd edition. London: Bloomsbury Academic.

Pridham, F. (2001).The Language of Conversation. London and New York: Routledge Taylor and Francis Group.

Sacks, H., Schegloff, E., and Jefferson, G. (1974).A Simplest Systematics for the Organization of Turn Taking in Conversation.Language, 50, 696-735.

Stenstrom, A. B. (1994). An Introduction to Spoken Interaction.London and New York: Longman.

Wong, J. and Waring, H. Z. (2010).Conversation Analysis and Second Language Pedagogy. A Guide for ESL/EFL Teachers. New York and London: Routledge Taylor and Francis Group.

Rose, R. L. (2012). A Brief Taxonomy of Hesitation Phenomena.http://filledpause.com/taxonomy.

Rymes, B. (2009). Classroom Discourse Analysis: A Tool for Critical Reflection. Cresskill, NJ: Hampton Press.

Thornbury, S. and Slade, D. (2006).Conversation: From Description to Pedagogy. Cambridge: Cambridge University Press. 